\title{
1919: la puerta de la Entreguerras; una Transición Inter-sistémica.
}

\author{
Patricia Kreibohm ${ }^{1}$
}

La Gran Guerra había terminado. Las potencias de la Triple Alianza habían sido derrotadas y se habían firmado los Acuerdos de París. Los líderes de la época, aspiraban a crear un nuevo mundo sin guerras y para ello, habían creado la Sociedad de las Naciones. Mientras tanto, Europa entraba en una nueva etapa; entraba en ella arruinada, agotada y desmoralizada. Las pérdidas materiales y humanas, la destrucción del sistema comercial y financiero de sus países, el desastre del aparato productivo y de las actividades agrícolas y artesanales, se sumaron a la sensación colectiva de inseguridad y desaliento. De hecho, ese continente que había sido el núcleo de la Civilización Occidental, sólo tenía fuerzas para abocarse a la lenta y penosa tarea de reconstrucción.

Cuatro imperios habían desaparecido. El primero fue el ruso, que cayó en 1917 ante las oleadas revolucionarias de Febrero y de Octubre. Cuando terminó la guerra, les tocó el turno a los otros tres: el alemán, el austríaco y el otomano. Esto generó un cambio sustancial en el mapa político de Europa pues, a partir de estas disoluciones, se crearon nuevos países: Checoslovaquia, Hungría, Yugoslavia, Turquía...

A los efectos de interpretar este período desde una perspectiva integral, que conjugue los hechos históricos con los modelos analíticos de las RRII, examinaremos esta etapa - bautizada Entreguerras, por los historiadores - como una Transición Inter-sistémica; es decir como un periodo en el cual el Modelo de Orden que regía hasta entonces, ha desaparecido y aún no se ha configurado uno nuevo.

Desde el punto de vista teórico, en una TIS (Transición Inter-sistémica) es habitual que convivan algunos elementos del viejo modelo con otros, totalmente novedosos. Según Da-

Doi: https://doi.org/10.24215/23142766e083

\footnotetext{
${ }^{1}$ Magister en Relaciones Internacionales (Universidad Nacional de Tucumán), coordinadora del Departamento de Historia de las Relaciones Internacionales del IRI-UNLP
} 
llanegra Pedraza, se trata de un periodo especial y complejo en el que los antiguos hegemones han perdido el poder y/o las capacidades que poseían; un periodo en el que las reglas y las pautas que habían regido hasta entonces, ya no son efectivas y, por lo tanto, los códigos y las pautas de la vida internacional se encuentran seriamente trastornadas. En otras palabras, los inicios de esta Transición pueden considerarse un tiempo cero, en el que todo está por organizarse.

Si la estructura se ha derrumbado y las leyes que la regulaban han desparecido, no existen parámetros para orientar las decisiones y las acciones. Esto hace que se trate de un tiempo absolutamente marcado por la coyuntura, en el cual sólo pueden apreciarse tendencias. Normalmente conflictiva, confusa y volátil, esta Transición no tiene una duración determinada.

"Lo cierto es que no hay un orden automático. Desaparecido un modelo de orden, no emerge uno nuevo en forma inmediata. Por el contrario, esto se da a través de un complejo proceso que requiere de bastante tiempo" ${ }^{2}$

Durante esta etapa, se dieron una serie de cambios significativos; entre ellos, se destacan los siguientes:

1. La Sociedad Internacional se convirtió en una sociedad euro americana, pues el predominio de los Estados Unidos en la escena internacional marcó una diferencia significativa con el periodo anterior.

2. Surgió la Sociedad de Masas, que sustituyó al mundo elitista y burgués que existía hasta entonces. Ligado a esta transformación, surgió un nuevo concepto: la justicia social.

3. A su vez, el protagonismo de los medios de comunicación masivos, fortaleció el peso de la opinión pública y cambió el rol de la mujer, quien se incorporó activamente como figura pública en la sociedad.

4. El Derecho a la Autodeterminación de los pueblos y el Principio de las Nacionalidades se consolidaron como principios relevantes.

5. Las nuevas ideas de Cooperación y Seguridad Colectiva, se configuraron como nuevos valores.

6. Aumentó el número de actores internacionales (nuevos Estados y Organizaciones Internacionales) ${ }^{3}$.

En general, y desde el punto de vista político, las instituciones democráticas y parlamentarias superaron la guerra sin sufrir daños aparentes, pero con el correr del tiempo, su fragilidad se hizo evidente. De hecho, y a pesar de que las democracias occidentales habían triunfado y de que sus regímenes políticos no se habían deteriorado en su estructura, ya no poseían la fuerza y el prestigio que tenían antes de la guerra. Esto impulsó a algunos gobiernos a llevar a cabo una serie de reformas: el sufragio universal masculino; la representación proporcional y el reconocimiento de derechos sociales y laborales. Sin embargo, en muchos casos (Inglaterra, Francia, Alemania), el Parlamento se vio obligado a disminuir sus atribuciones y a permitir al ejecutivo que legislara. En efecto, en estos tiempos de crisis, era habitual que los presidentes recurrieran a los decretos, lo cual fortaleció su poder.

\footnotetext{
2 Dallanegra. Pedraza, La configuración del Orden Mundial. Ed del Autor. P3

${ }^{3}$ Pereira Castañares, Juan Carlos, "Un siglo de cooperación y conflicto. Las relaciones internacionales desde la perspectiva del presente", Cuadernos e Historia Contemporánea, número 21, 1999, Departamento de Historia Contemporánea (UCM). Pp. 17-62.
} 
Sin embargo, en otros países, las democracias habían sucumbido. En los primeros años de la década del 20, ya habían surgido dos modelos políticos autoritarios que, rápidamente, se convirtieron en totalitarios: el Comunismo ruso y el Fascismo italiano. En esta época además, los resentimientos y los rencores de los vencidos y de los que no estaban conformes con los resultados obtenidos, se potenciaron durante los primeros años de la posguerra y sus frustraciones fueron capitalizadas por nuevos líderes y grupos. Los casos paradigmáticos son los de Italia, Alemania y Japón. Sin embargo, el nacionalismo no se limitó a estos países; Francia y Estados Unidos, cuyas sociedades eran conservadoras y xenófobas, también lo padecieron. EEUU cerró sus puertas a la inmigración y entre los franceses creció un nacionalismo alimentado por el orgullo de la victoria, el progreso económico y la supuesta superioridad cultural. No obstante, las decepciones provocadas por los magros beneficios de la paz y la demora en el cobro de las indemnizaciones de guerra, generaron conductas intolerantes y alimentaron movimientos en favor del rearme.

Por otra parte, las heridas de la guerra no habían terminado de cicatrizar. Los temores y las desconfianzas de pueblos y líderes, se percibían como una atmósfera pesada que enturbiaba sistemáticamente las relaciones; las relaciones entre los pueblos y sus gobiernos y las relaciones de los Estados entre sí.

Examinemos algunos casos.

\section{Inglaterra y Francia.}

Inglaterra salió muy debilitada de la guerra y perdió su posición de primera potencia mundial. Sin embargo, y a pesar de las dificultades internas, su régimen parlamentario permaneció estable. La desocupación, la crisis y las huelgas obreras, configuraron una situación difícil, pero a partir del año 26, el panorama mejoró. Desde entonces, el movimiento obrero y los empresarios lograron mantener relaciones armónicas basadas en el diálogo y el entendimiento; se consolidó la democracia mediante el sufragio universal masculino (1918) y el de las mujeres mayores de 30 años (1921) y se dieron reformas sociales tales como el seguro de desempleo en 1920 y la ley de pensiones en 1925.

La política británica estaba encabezada por hombres moderados, decididos a conservar la democracia, lo cual - unido a una importante cohesión interna sostenida por un sentimiento hacia la unidad - fue la clave del éxito británico para superar la coyuntura.

La situación de Francia era similar aunque más conflictiva. La desocupación, las huelgas y la inmovilidad de la economía acarrearon serias dificultades al país. Desde un punto de vista político, el sistema electivo proporcional impedía la formación de grandes mayorías parlamentarias ocasionando la inestabilidad de los gabinetes, que terminaron convirtiéndose en sistemas de coalición.

\section{Alemania.}

En noviembre de 1918, la monarquía fue sustituida por un régimen constitucional democrático que se consagró en la ciudad de Weimar. Este sistema nació débil y, en su corta historia, debió soportar muchas amenazas. El primer gobierno que se instauró fue de tendencia socialista moderada y su oposición más fuerte fueron los socialistas extremos y los comunistas.

En enero de 1919, los Espartaquistas (comunistas) organizaron una revolución que fue sofocada. Sus líderes, Liebcknecht y Rosa Luxemburgo fueron asesinados. También hubo 
intentos golpistas de la derecha que también fracasaron; el más importante fue el que llevó a cabo Adolf Hitler en 1923. Sin embargo, el nacionalismo fue creciendo, sobre todo en base a la penuria económica que padecían los alemanes, motivada sobre todo por: la crisis inflacionaria del 23 - producida por la deuda interna que había generado el Estado - la emisión de moneda y el pago de las reparaciones de guerra.

Como señalan los historiadores, al principio, los grupos de derecha - al igual que los comunistas - no representaron un peligro para la república de Weimar, sin embargo, la inflación exacerbó las divisiones sociales y económicas y provocó la pérdida de apoyo a los partidos liberales, democráticos y de centro. Los grupos nacionalistas alemanes criticaban a la república, fundamentalmente por la incapacidad del gobierno para revertir la situación, para dar salida a las necesidades de la población y para modificar un esquema de funcionamiento al que consideraban corrupto e inoperante. Frente a la debilidad y el desprestigio de los políticos, el ejército y la industria favorecieron el desarrollo de asociaciones nacionalistas que propugnaban ideas anticomunistas, antisemitas y antidemocráticas. Poco tiempo después, los efectos de la crisis de 1929, constituyeron un fuerte impulso para estos sectores. Así, en poco tiempo, se configuró un nacionalismo xenófobo, que acabaría en la gestación del III Reich de Adolfo Hitler.

\section{Italia}

El caso italiano es particularmente interesante pues, a pesar de que había estado en el bando ganador, el país tenía severos problemas. Para empezar, no se le concedieron los territorios y los beneficios que se le habían prometido en 1915 (Pacto de Londres) lo cual había generado una gran frustración colectiva. En segundo término, los padecimientos de la guerra aceleraron el empobrecimiento de la clase media y esta situación se complicó con el incremento de la desocupación en las ciudades, las ansias de tierras del campesinado y la desilusión en la democracia.

De hecho, desde la finalización de la guerra, el nivel de violencia callejera fue cada vez mayor y los enfrentamientos entre la izquierda y la derecha debilitaron sistemáticamente a una monarquía agotada y cada vez más impotente.

Para intentar paliar la situación, en 1919 se hicieron reformas electorales: sufragio universal y representación proporcional; dos medidas que restaron votos a los partidos liberales. En esta coyuntura, nacieron los Fascios di Combattimento; un conjunto de sectores organizados y liderados por Benito Mussolini, que iniciaron manifestaciones callejeras. Entre 1919 y 1921, los gobiernos liberales trataron de resolver las tensiones, pero fracasaron. Ante esto, las clases medias abandonaron en masa el partido liberal, pues sentían que no respondía a sus demandas: la inflación, la violencia callejera, el miedo a la revolución comunista y el descontento con los tratados de paz.

Paulatinamente, estos sectores medios empezaron a apoyar a Mussolini que, desde fines de 1921, ofrecía un programa con soluciones para todos los sectores. Entre sus puntos más importantes, figuraban: acabar con las huelgas, poner fin a los desórdenes, disciplinar a los trabajadores y crear un nuevo destino de gloria y grandeza para Italia; un orden inspirado en el imperio romano y en el renacimiento.

En 1922, los Fascios, más organizados y con el apoyo del ejército y la complicidad del gobierno, llevaron a Mussolini al poder.

\section{Europa Central y Oriental}


La situación de los estados de Europa oriental, tanto los nuevos como los antiguos, era muy diferente. Si bien en 1921 ya se habían celebrado elecciones libres en Finlandia, en las repúblicas bálticas (Letonia, Estonia y Lituania), Polonia, Rumania, Checoeslovaquia, Austria, Hungría, Yugoslavia y Bulgaria, las diferencias sociales eran enormes. Dichas diferencias se acentuaban por la enorme diversidad de lenguas, religiones e historias de los nuevos Estados. En general, las constituciones daban un importante papel al poder legislativo; sin embargo, este sistema, en sociedades tan divididas, pobres y carentes de experiencia democrática, causó enormes problemas. Esto motivó que la inestabilidad y la violencia, se convirtieran en los signos distintivos de la política del Este. De hecho, entre el 1918 y 1919 estallaron en Austria y Hungría varias revoluciones comunistas que fueron sofocadas y dieron lugar a la instalación de gobiernos de derecha.

Con respecto a los problemas fundamentales de la Europa Oriental, los más importantes fueron: la convivencia de las distintas nacionalidades; las diferencias sociales y culturales y, a nivel económico, la carencia de capitales, inversión y mano de obra calificada.

\section{Las Relaciones Internacionales entre 1919 y 1929.}

Desde el punto de vista de las relaciones internacionales, este período se puede dividir en dos etapas: la primera desde 1918 a 1924 - un período de tensión - y la segunda, desde el año 25 al 29, más parecida a una distención.

El elemento más problemático de la situación fue la cuestión económica, causada por las reparaciones, las deudas y la política indiferente de los EE.UU. para solucionar los problemas internacionales en un marco de solidaridad.

Recordemos que la paz se había firmado sin el convencimiento de muchos y, según algunos autores, esto había motivado el surgimiento de una especie de máquina diplomática que iba destruyendo los pactos que se habían rubricado. De hecho, ya en 1919, se realizaron rectificaciones a los tratados debido a dos cuestiones cruciales: la seguridad de Francia y el pago de las reparaciones de guerra de Alemania

El origen de la tensión se originó en la negativa de EEUU a ratificar el Tratado de Versalles y el pacto de la Sociedad de las Naciones; acontecimientos que ocurrieron porque Wilson perdió las elecciones. Al retirarse EEUU, Francia se vio privada de uno de los soportes que le brindaban seguridad frente a Alemania. Por su parte, Inglaterra consideró que su compromiso con Francia no era tan grande; en efecto, los ingleses se sentían seguros en su insularidad y dejaron sin efecto el tratado de ayuda inmediata a Francia en caso de agresión alemana. De hecho, Inglaterra y Francia tenían distintas posturas respecto de la seguridad: para Francia la seguridad pasaba por el estricto cumplimiento del Tratado de Versalles y consideraba que su seguridad dependía del mantenimiento de la fuerza, a fin de controlar a Alemania. Por su parte, Inglaterra tenía una cierta indulgencia con Alemania y estaba dispuesta a revisar el Tratado de Versalles.

En resumen, los desacuerdos entre Francia e Inglaterra eran varios, pero podemos sintetizarlos en 4 puntos fundamentales: el cumplimiento del pago de las reparaciones, el desarme alemán, el problema de la Alta Silesia (frontera oriental de Alemania) y el problema de las fronteras de Alemania (sobre todo la frontera con Polonia, que era rechazada por la opinión pública alemana).

En esta coyuntura, Francia firmó un pacto defensivo con Polonia (1921) y más tarde con Checoeslovaquia, Rumania y Yugoslavia. En esta Pequeña Entente, Inglaterra no quiso participar. 
La cuestión de las reparaciones también era seria pues los alemanes no pagaban como correspondía. La crisis económica, la destrucción de la guerra y las debilidades del gobierno, eran elementos que, de alguna manera, explicaban sus atrasos. Sin embargo, estas razones no contribuían a calmar los ánimos. La postura francesa era muy dura con respecto a esto, mientras que Inglaterra pensaba que era necesario renegociar las condiciones de la deuda, de otro modo- Alemania no podría recuperarse nunca. ${ }^{4}$ Por otra parte, hay que recordar que Francia e Inglaterra habían sido rivales desde siempre, e Inglaterra tampoco quería que Francia se convirtiera en una potencia hegemónica. Lloyd George (el Primer Ministro inglés) decidió que lo mejor era tratar de volver a la vieja concepción del equilibrio europeo y para ello, necesitaba que Alemania se recuperase. Por otra parte, los ingleses temían al comunismo y a la posibilidad de que los socialistas triunfaran en Alemania. La situación empeoró cuando EEUU - que atravesaba una crisis económica en 1922 - exigió a los aliados el pago de las deudas. No olvidemos que el tesoro norteamericano había prestado enormes cantidades de dinero tanto a Francia como a Inglaterra durante la guerra.

En 1923, ante los incumplimientos de Alemania en el pago de las reparaciones, Francia y Bélgica decidieron ocupar militarmente la cuenca del Rhur, y mandaron ingenieros a controlar las minas de carbón a fin de que los obreros alemanes cumplieran con las cuotas de producción establecidas. Los alemanes respondieron entonces con una resistencia pasiva y paralizaron la producción. La economía alemana se vio muy afectada y entró en un espiral inflacionario, que acabó en una hiper-inflación. Finalmente, la llegada de nuevos créditos de los EEUU (Plan Dawes), el Pacto de Locarno y otras decisiones, hicieron pensar que la voluntad de solucionar las diferencias iba a triunfar sobre los resquemores. De hecho, la renuncia a la guerra, manifestada claramente en el Pacto Briand-Kellog en 1928, significó un hito en las aspiraciones colectivas. Pero, una vez más, la ilusión duraría muy poco tiempo.

En definitiva, nada ni nadie podía confiar en que la tranquilidad y la confianza condujeran las relaciones internacionales. Por el contrario, año a año era evidente que esa $P a z$ cartaginesa que se había firmado en Versalles, era incapaz de garantizar la estabilidad del continente.

En la década siguiente (los años 30) los conflictos encendieron nuevamente la tensión. Y en esta oportunidad, ya no hubo vuelta atrás.

En otras palabras, es evidente que esa inestabilidad - propia de la TIS - marcó las relaciones del periodo; un periodo indudablemente inseguro, vacilante y peligroso. De hecho, y a partir de la consolidación de los totalitarismos, se inició lo que los autores identifican como: el proceso de polarización; es decir, el inicio de una nueva competencia entre los actores que aspiraban a convertirse en los nuevos hegemones. ${ }^{5}$ Dicho proceso, que puede darse mediante diversas vías, determinó el incremento de los conflictos y desembocó en una Guerra Total. Una guerra que no sólo cerró el periodo de la TIS, sino que dio lugar a la configuración de un nuevo Modelo de Orden: el Sistema Bipolar. Esta vez los líderes no eran europeos: los EEUU y la URSS.

\footnotetext{
${ }^{4}$ Francia había sido invadida por los alemanes y sus territorios y población habían sufrido enormemente a consecuencia de ello, el resentimiento y la dureza de Francia era completamente comprensible.

${ }^{5}$ El proceso de polarización es típico de la TIS. Puede darse de manera violenta o no violenta y, cuando culmina, da origen a un nuevo Modelo de Orden
} 